\title{
PERANCANGAN ULANG PROSES UNTUK MEREDUKSI WAKTU PROSES DAN MENINGKATKAN KAPASITAS PRODUKSI YANG LEBIH EFEKTIF AGAR DAPAT MENINGKATKAN PENDAPATAN
}

\author{
Chevy Herli Sumerli A. ${ }^{1}$, Putri Mety Zalynda ${ }^{2}$. \\ ${ }^{1,2}$ Teknik Industri, Universitas Pasundan, Bandung \\ chevy.herlys@unpas.ac.id, putri.mety@unpas.ac.id
}

\begin{abstract}
Abstrak
Desa Genteng berada di Kecamatan Sukasari Kabupaten Sumedang. Dengan sumber daya alam yang melimpah berupa bambu, yang tumbuh liar begitu saja. Ini menjadi mata pencaharian penduduk yaitu kerajinan dari bambu, mengolah bambu menjadi berbagai produk kerajinan diantaranya adalah boboko (bakul), nyiru (ampan), hihid (kipas), ayakan (saringan), dingkul (tempat menyimpan perkakas). Hasil anyaman seperti boboko (bakul), biasanya dijual ke bandar Rp 10 ribu/buah. Satu orang warga bisa memproduksi sebanyak tiga boboko(bakul) dalam waktu satu hari. Para pengrajin bambu baru memilih mengolah bambu bagian batangnya menjadi iratan kemudian menganyamnya menjadi beberapa produk. Tujuan yang ingin dicapai adalah membantu dengan membuatkan rancangan proses baru dengan menggunakan mesin pembuat iritan bambu agar prosesnya menjadi lebih cepat dan sekaligus bisa meningkatkan kapasitas produksi. Bambu dengan panjang ruas 45-65 $\mathrm{cm}$ dan ketebalan $15 \mathrm{~mm}$ untuk dijadikan iritan bambu setebal $2 \mathrm{~mm}$ jika menggunakan mesin akan dihasilkan 7 iritan bambu dalam waktu 2 detik. Sedangkan jika manual menggunakan pisau memerlukan waktu 60 detik. Sehingga iritan bambu yang disiapkan lebih banyak dan diharapkan boboko yang bisa dibuat dalam satu hari menjadi lebih banyak lagi.
\end{abstract}

Kata Kunci : Pengolahan Bambu, Perancangan Proses, Waktu Proses

\section{PENDAHULUAN}

Desa Genteng merupakan sebuah desa yang berada di wilayah Kecamatan Sukasari Kabupaten Sumedang. Desa Genteng memiliki luas wilayah sebesar 1.371 hektar. Luasan lahan berupa pesawahan mencakup wilayah seluas 134 hektar, dan lahan pertanian non-pesawahan seluas 1.132 hektar. Sisanya seluas 105 hektar dipergunakan untuk keperluan non-pertanian seperti lahan pemukiman dan pekarangan, lahan fasilitas umum dan yang lainnya.
Dengan sumber daya alam yang melimpah berupa bambu, yang tumbuh liar begitu saja. Ini menjadi satu lagi sektor yang menjadi mata pencaharian sebagian penduduk yaitu kerajinan dari bambu, mengolah bambu menjadi berbagai produk kerajinan diantaranya adalah boboko (bakul), nyiru (ampan), hihid (kipas), ayakan (saringan), dingkul (tempat menyimpan perkakas). Lebih dari 100 kepala keluarga (KK) saat ini bermata pencaharian sebagai perajin bambu. Usaha tersebut, merupakan warisan leluhur warga setempat dan telah digelutinya sejak puluhan tahun silam. Sehingga, 
semua warga termasuk anak-anak, remaja, dewasa, dan orangtua, dipastikan bisa menganyam bambu. Sepulangnya warga dari sawah dan kebun disibukan dengan menganyam. Meski begitu, kondisi perekonomian warga yang didominasi pengrajin bambu itu, masih cukup memprihatinkan. Dengan keterbatasan modal, mereka kesulitan dalam memasarkan hasil anyaman tersebut. hasil anyaman seperti bakul, nampan, ayakan, dan tolombong, biasanya dijual ke bandar Rp $10 \mathrm{ribu} / \mathrm{buah}$. Untuk satu jenis kerajinan berukuran seperti tempat nasi misalnya, satu orang warga bisa memproduksi sebanyak tiga buah kerajinan dalam waktu satu hari.

Pengrajin baru memanfaatkan salah peluang saja dari mengolah bambu, baru mengupayakan satu ranting dari satu bagian saja dari pohon industri bambu. Para pengrajin bambu di Desa Genteng Kecamatan Sukasari, baru memilih mengolah bambu bagian batangnya menjadi iratan kemudian menganyamnya menjadi beberapa produk.

\begin{tabular}{|c|c|c|c|c|}
\hline No & $\begin{array}{l}\text { Bagian } \\
\text { Pohon } \\
\text { Bambu } \\
\end{array}$ & Proses & $\begin{array}{l}\text { Sudah Diolah } \\
\text { Menjadi }\end{array}$ & Belum Diolah \\
\hline \multirow[t]{4}{*}{1} & \multirow[t]{4}{*}{ Batang } & $\begin{array}{l}\text { Iratan } \\
\text { (anyaman) }\end{array}$ & $\begin{array}{l}\text { Boboko, } \\
\text { Besek, Nyiru, } \\
\text { Hihid, } \\
\text { Ayakan, } \\
\text { Dingkul, } \\
\text { Topi, Bilik }\end{array}$ & $\begin{array}{l}\text { Aneka } \\
\text { Keranjang }\end{array}$ \\
\hline & & $\begin{array}{l}\text { Dibelah- } \\
\text { belah }\end{array}$ & $\begin{array}{l}\text { Tusuk Sate, } \\
\text { Rarancang } \\
\text { Layanan }\end{array}$ & $\begin{array}{l}\text { Krei, Sangkar } \\
\text { Burung, } \\
\text { Sumpit }\end{array}$ \\
\hline & & Utuh & & $\begin{array}{l}\text { Meja, Kursi, } \\
\text { Alat Musik }\end{array}$ \\
\hline & & $\begin{array}{l}\text { Pulp } \\
\text { Bambu }\end{array}$ & & $\begin{array}{l}\text { Kertas, } \\
\text { Tekstile }\end{array}$ \\
\hline 2 & Daun & & & $\begin{array}{l}\text { Pewarna } \\
\text { Alami, } \\
\text { Kemasan } \\
\text { Makanan, } \\
\text { Pupuk, Pakan } \\
\text { Ternak, Obat }\end{array}$ \\
\hline 3 & $\begin{array}{l}\text { Pelepah } \\
\text { Batang }\end{array}$ & & & Kertas Seni \\
\hline 4 & Akar & & & $\begin{array}{l}\text { Aneka } \\
\text { Kerajinan } \\
\text { Ukir dan } \\
\text { Tatah }\end{array}$ \\
\hline 5 & Ranting & & & Kerajinan \\
\hline 6 & Rebung & & & $\begin{array}{l}\text { Makanan, } \\
\text { Obat }\end{array}$ \\
\hline 7 & $\begin{array}{l}\text { Semua } \\
\text { Bagian } \\
\text { Bambu }\end{array}$ & & & TAR (Bio Oil) \\
\hline
\end{tabular}

Adapun tujuan dari kegiatan Pengabdian Pada Masyarakat (PPM) Program Studi Teknik Industri Unpas ini adalah meningkatkan pengetahuan dan pemahaman kepada pengrajin dan masyarakat umum agar lebih mampu dan mau mencoba untuk menghasilkan produk dari berbagai macam pengolahan semua bagian dari pohon bambu agar bernilai ekonomis dengan nilai tambah yang tinggi. Sehingga memiliki peluang pendapatan yang lebih banyak dan lebih tinggi. Maka perlu dibuat rancangan produk dan rancangan proses serta produksinya untuk mengolah semua bagian dari pohon bambu, beserta diferensiasi produknya. Perlu dibuat rencana penanaman bibit pohon bambu, untuk keberlangsungan dan keberlanjutan IKM Bambu ini.

Berbagai hasil penelitian tentang bambu yang menjadi referendi penelitian ini. Penelitian pertama tentang berbagai manfaat bambu, yaitu manfaat secara ekologi, manfaat sebagai bahan baku industry, dan manfaat secara social ekonomi (Widnyana, n.d.). Penelitian kedua tentang teknologi yang digunakan untuk mengolah bambu menjadi wood pellet, menjadi bambu lamina, menjadi inti kayu lapis, menjadi arang bambu, dan menjadi pulp (Arsad, 2015). Penelitian ketiga tentang analisis kelayakan finansial usaha budidaya bambu berdasarkan kriteria NPV, Net B/C, IRR, dan Payback Period. Semua aspek finansial menunjukan bahwa usaha ini layak untuk dijalankan (Khotimah, 2014). Penelitian keempat proses pembuatan anyaman bambu terdiri dari pengulitan dan pembelaham bambu, pembuatan iratan, penghalusan iratan, penjemuran iratan, dan diakhiri dengan penganyaman. Dalam penelitian ini diidentifikasi bahwa faktor produksi yang paling berpengaruh adalah ukuran (panjang-pendek) iratan (Asriyati, 2019). Penelitian kelima adalah perubahan dari penggunaan alat-alat tradisional menjadi menggunakan mesin penyerut bambu untuk meningkatkan produktivitas produksi kerajinan bambu (Zuldesmi, 2018). Penelitian keenam adalah upaya peningkatan kualitas serutan bambu dengan menggunakan mesin penyerut bambu (Yuniwati et al., 2021). Penelitian ketujuh adalah upaya 
pemberdayaan kelompok pengrajin bambu melalui pelatihan peningkatan produktivitas dan menambah ragam produk yang dihasilkan kelompok (Krisnaresanti et al., 2020). Ketujuh jurnal tersebut menjadi dasar ide rencana pengabdian kepada masyarakat yang akan dilakukan oleh Program Studi Teknik Industri Universitas Pasundan bertahap selama 5 tahun kedepan.

\section{METODE}

Menjelaskan langkah-langkah sistematis yang dilakukan dalam kegiatan pengabdian kepada masyarakat. Metode pelaksanaan pada kegiatan ini dimulai dengan membuat beberapa skenario yang mungkin terjadi. Berikutnya menjelaskan tahapan atau langkah-langkah dalam melaksanakan solusi untuk mengatasi permasalahan.

Beberapa skenario yang mungkin terjadi adalah : 1). Jika tidak diberikan stimulus untuk berubah, maka para pengrajin di Desa Genteng ini tidak akan berubah. Para pengrajin di Desa Genteng ini akan tetap hanya menganyam membuat boboko dan peralatan dapur lainnya saja, dengan jumlah produk yang dihasilkan setiap harinya tetap dari waktu ke waktu; 2). Jika diberikan stimulus untuk berubah, maka para pengrajin di Desa Genteng ini berubah menjadi lebih baik, dengan alternatif sebagai berikut : a). Para pengrajin di Desa Genteng ini tetap bisanya menganyam membuat boboko dan peralatan dapur lainnya, tetapi dapat meningkatkan jumlah produk yang dihasilkan perharinya; b). Para pengrajin di Desa Genteng ini selain tetap mengayam membuat boboko dan peralatan dapur, serta bisa menganyam produk lain yang memiliki nilai tambah yang lebih tinggi, apalagi iratannya tersedia cukup banyak; c). Para pengrajin di Desa Genteng ini selain tetap bisa menganyam, juga bisa mengolah batang pohon bambu dengan cara yang lain; d). Para pengrajin di Desa Genteng ini selain bisa memproses batang pohon bambu, tetapi bisa memproses atau mengolah bagian lainnya dari pohon bambu yang selama ini tidak diproses atau bahkan dibuang atau dibiarkan sebagai sampah; 3). Bahkan Ketika diberikan stimulus untuk berubah, para pengrajin di Desa Genteng ini bisa berubah bukan hanya menjadi lebih baik, tetapi mencapai spesifikasi produk yang memenuhi kualitas untuk ekspor; 4). Yang sangat tidak diharapkan adalah ketika diberikan stimulus untuk berubah, tetapi para pengrajin di Desa Genteng ini tidak berubah menjadi lebih baik.

Tahapan yang dilakukan untuk memecahkan masalah Pengrajin dan Masyarakat Desa Genteng Kecamatan Sukasari adalah sebagai berikut : 1). Membuat rancangan produk dari semua bagian dari pohon bambu yang belum pernah dibuat; 2). Mempelajari dan memahami proses membuat produk berdasarkan rancangan produk di atas; 3). Merancang proses produksi agar dari setiap batang pohon bambu semuanya bisa menjadi produk atau bagian dari produk sehingga tidak ada yang terbuang; 4). Membuat rencana penanaman berkala, agar ketersediaan bahan baku bisa berkelanjutan.

Tahapan yang diusulkan untuk mengatasi persoalan Bidang Perancangan Produk tersebut di atas, yaitu Para Pengrajin tetap seperti sekarang ini, mengolah bambu bagian batangnya menjadi iratan kemudian menganyamnya menjadi beberapa produk, seperti membuat boboko (bakul), nyiru (ampan), hihid (kipas), ayakan (saringan), dingkul (tempat menyimpan perkakas), dan segala macam perkakas rumah tangga berbahan dasar bambu. Tetapi tidak menghabiskan semua bahan baku batang bambu untuk membuat produk tersebut di atas. Berikutnya mencoba rancangan produk lain, yaitu keranjang. Seperti Kita ketahui bahwa permintaan keranjang dari rotan sangat tinggi apalagi pada saat menjelang Hari Natal dan Tahun Baru Masehi, keranjang dari bahan bambu bisa menjadi alternatif atau pesaing keranjang dari rotan.

Tahapan yang diusulkan untuk mengatasi persoalan Bidang Produksi tersebut di atas, yaitu : Para Pengrajin tetap seperti sekarang ini, mengolah pohon bambu bagian batangnya menjadi iratan kemudian menganyamnya menjadi beberapa produk, seperti membuat boboko (bakul), nyiru (ampan), hihid (kipas), ayakan (saringan), dingkul (tempat menyimpan perkakas), dan segala macam perkakas rumah tangga berbahan dasar bambu, tetapi dengan jumlah produk yang dihasilkan lebih banyak perharinya dari sebelumnya. Hal ini bisa terjadi karena ketersediaan iratan yang cukup banyak, yang proses membelah-belah bambunya dibantu alat pembelah dan membuat iratannya 
dibantu dengan mesin serut bambu, seperti berikut ini :

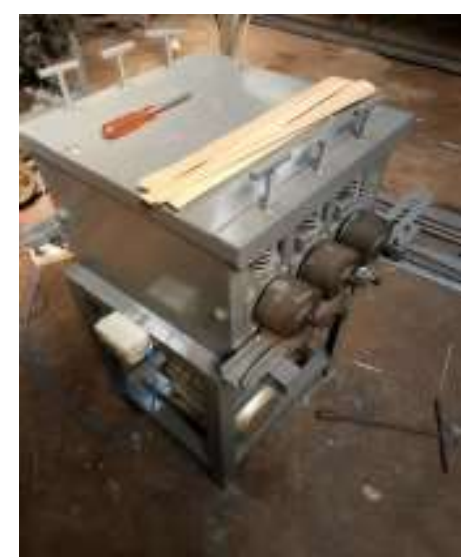

Gambar 1. Mesin Serut Bambu Kapasitas Besar Bertenaga Listrik
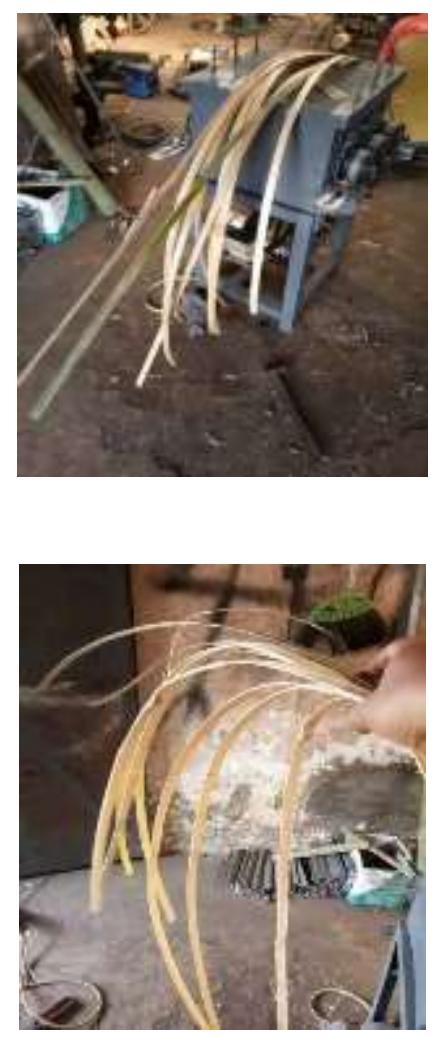

Gambar 2. Iratan Hasil Mesin Serut Bambu Kapasitas Besar Bertenaga Listrik

\section{HASIL DAN PEMBAHASAN}

Hasil pelaksanaan pada kegiatan ini berdasarkan beberapa skenario yang mungkin terjadi. Berikutnya menbahas tahapan atau langkah-langkah dalam melaksanakan solusi untuk mengatasi permasalahan.

Berdasarkan Skenario-2 bahwa jika diberikan stimulus untuk berubah, maka para pengrajin di Desa Genteng ini ingin berubah menjadi lebih baik, dibuktikan dengan surat kesediaan kerjasama dari para pengrajian untuk mengikuti program perubahan tersebut.

Berdasarkan empat alternatif hasil dari Skenario-2, maka yang dicapai pada tahap-1 adalah : Para pengrajin di Desa Genteng ini tetap bisanya menganyam membuat boboko dan peralatan dapur lainnya, tetapi dapat meningkatkan jumlah produk yang dihasilkan perharinya.

Urutan proses membuat Boboko dimulai dari $\rightarrow$ Bambu dipotong - potong per ruas dan dibuang buku-bukunya $\rightarrow$ Belah-belah menjadi bentuk lembaran, bagian paling dalam digunakan untuk kaki bakul $\rightarrow$ Lembaran bambu dijemur sampai kering $\rightarrow$ Belah lagi menjadi iratan berukuran kurang lebih $0,2 \mathrm{~cm} \rightarrow$ Dianyam $\rightarrow$ Bagian atasnya diberi bambu yang melingkar $\rightarrow$ Bagian bawahnya diberi kaki dari bambu bagian dalam tadi. Proses membuat iratan setebal $0,2 \mathrm{~cm}$ yang semula menggunakan pisau dirubah menjadi menggunakan Mesin serut pembuat iratan.

Dengan bantuan mesin penyerut bambu diharapkan ketersediaan iratan semakin banyak, sehingga dapat meningkatkan kapasitas produksi dan produk yang dihasilkan perorang/perhari meningkat 30-100\%. Hasil ini bisa dicapai oleh Kelompok Pengrajin dengan membuatkan rancangan proses baru dengan menggunakan mesin pembuat iritan bambu agar prosesnya menjadi lebih cepat dan sekaligus bisa meningkatkan kapasitas produksi. Bambu dengan panjang ruas $45-65 \mathrm{~cm}$ dan ketebalan $15 \mathrm{~mm}$ untuk dijadikan iritan bambu setebal $2 \mathrm{~mm}$ jika menggunakan mesin akan dihasilkan 7 iritan bambu dalam waktu 2 detik. Sedangkan jika manual menggunakan pisau memerlukan waktu 60 detik. Sehingga iritan bambu yang disiapkan lebih banyak dan diharapkan boboko yang bisa dibuat dalam satu hari menjadi lebih banyak lagi. Yang semula satu orang warga 
bisa memproduksi sebanyak tiga boboko dalam waktu satu hari, minimal bisa menambah 1 boboko lagi hingga 3 boboko. Sehingga pendapatan perorang yang biasanya Rp. 30.000 perhari bisa mencapai hingga Rp. 60.000 Dan bisa perhari. Dan Kelompok Pengrajin Bu Wiwin yang semula 5 orang bisa menambah jumlah anggota kelompoknya 5 orang lagi karena jumlah iritan yang dihasilkan perharinya bisa 30 kali lebih banyak.

Melanjutkan dari Skenario-2, maka yang dicapai pada tahap-2 pada khususnya untuk Pengrajin Kelompok adalah : Para pengrajin di Desa Genteng ini selain tetap mengayam membuat boboko dan peralatan dapur, serta bisa menganyam produk lain yang memiliki nilai tambah yang lebih tinggi, apalagi iratannya tersedia cukup banyak.

Hasil bantuan mesin pembelah bambu dan/atau mesin penyerut bambu yang menyebabkan ketersediaan iratan semakin banyak, sehingga dapat meningkatkan kapasitas produksi dan produk yang dihasilkan perorang/perhari meningkat 30-100\%.

Untuk menjaga agar produk boboko dan peralatan dapur lainnya tidak over production, maka para pengrajin seperti Kelompok Pengrajin-1 yang dipimpin Ibu Wiwin dapat menganyam produk lain seperti keranjang. Oleh karena itu dibuat rancangan produk keranjang, mencoba untuk membuatnya, berlatih terus sampai bisa dan biasa. Sehingga Kelompok Pengrajian-1 ini selain menghasilkan boboko dan peralatan dapur yang banyak, juga menghasilkan produk yang diperlukan oleh kelompok konsumen yang berbeda. Apalagi menjelang Hari Natal dan Tahun Baru permintaan keranjang meningkat.

\section{KESIMPULAN}

Teridentifikasi peluang berbagai proses pengolahan dari berbagai bagian dari pohon bambu menjadi produk yang bisa dilakukan oleh masyarakat Desa Genteng Kecamatan Sukasari. Dilakukan tahapan yang terukur agar tidak berubah mendadak dan drastis. Dimulai dengan pengadaan mesin yang membantu memecahkan persoalan bottleneck yang selama ini terjadi sehingga sulit berubah, proses berubah, waktu proses berubah, jumlah boboko yang dihasilkan berubah, pendapatan perharinya pun berubah.

Baru selanjutnya berubah untuk sesuatu yang baru, memulai membuat produk baru.

\section{REFERENSI}

Arsad, E. (2015). TEKNOLOGI PENGOLAHAN DAN MANFAAT BAMBU. Jurnal Riset Industri Hasil Hutan, $7(1), \quad 45$. https://doi.org/10.24111/jrihh.v7i1.856

Astuti, R. D., Budiyanto, T., \& Faishal, M. (2018). PEMBERDAYAAN WARGA MELALUI USAHA PEMBUATAN BESEK DI GUMAWANG GUNUNG KIDUL. Jurnal Pemberdayaan: Publikasi Hasil Pengabdian Kepada Masyarakat, 2(2), 297. https://doi.org/10.12928/jp.v2i2.386

Kartika, M., Hendarmin, H., \& Pebrianti, W. (2018). Pelatihan Dan Pendampingan Pengolahan Komoditi Kelapa. JPPM (Jurnal Pengabdian dan Pemberdayaan Masyarakat), 2(1), 1. https://doi.org/10.30595/jppm.v2i1.1706

Krisnaresanti, A., Naufalin, L. R., \& Dinanti, A. (2020). Pemberdayaan Kelompok Pengrajin Bambu "Kriya Mandiri" Desa Karangtengah Baturraden Melalui Pelatihan Peningkatan Produktivitas Kelompok. 2(2), 6.

Kristanto, A. (2012). PERANCANGAN MESIN PENYAYAT BAMBU SECARA ERGONOMIS. Jurnal Ilmiah Teknik Industri, 11(2), 12.

Lubis, U., \& Damayanti, R. A. (2014). EKSISTENSI MEBEL BAMBU DI TENGAH PERKEMBANGAN DESAIN DAN TEKNOLOGI. Jurnal Dimensi Seni Rupa dan Desain, 11(2), 135. https://doi.org/10.25105/dim.v11i2.107

Waluyo, S. (n.d.). [TESTING OF BAMBOO SPLITTER TOOL PROTOTYPE]. $1,8$.

Widnyana, K. (n.d.). BAMBU DENGAN BERBAGAI MANFAATNYA. 11. 
Winerungan, R. R. (2018). Penggunaan Alat Penyerut untuk Meningkatkan Produksi Kerajinan Bambu pada Kelompok Pengrajin di Kota Tomohon. 20(1), 5.

Wulandari, N. T., Darwanto, D. H., \& Irham, I. (2016). ANALISIS NILAI TAMBAH DAN KONTRIBUSI INDUSTRI KERAJINAN BAMBU PADA DISTRIBUSI PENDAPATAN MASYARAKAT DI KABUPATEN SLEMAN. Agro Ekonomi, 26(2), 192. https://doi.org/10.22146/agroekonomi.17271
Yuniwati, I., Fiveriaty, A., Rahayu, N. S., Azizi, M. R., \& Affandi, M. N. (2021). Penerapan mesin penyerut bambu pada pengrajin bambu irat sebagai upaya peningkatkan kualitas serutan bambu. Jurnal Inovasi Hasil Pengabdian Masyarakat (JIPEMAS), 4(1), 46. 